\title{
Juice Powder Concentrate and Systemic Blood Pressure, Progression of Coronary Artery Calcium and Antioxidant Status in Hypertensive Subjects: A Pilot Study
}

\author{
M. C. Houston ${ }^{1}$, B. Cooil ${ }^{2}$, B. J. Olafsson ${ }^{3}$ and P. Raggi ${ }^{4}$ \\ ${ }^{1}$ Hypertension Institute of Nashville, Vanderbilt University School of Medicine and Saint Thomas Hospital, \\ ${ }^{2}$ Owen Graduate School of Management, Vanderbilt University, ${ }^{3}$ The Heart Group, Saint Thomas Heart \\ Institute and Saint Thomas Hospital, Nashville, TN and ${ }^{4}$ Department of Medicine and Division of Cardiology, \\ Emory University School of Medicine, Atlanta, Georgia, USA
}

\begin{abstract}
Because micronutrients from plants may have beneficial cardiovascular effects, the hypothesis that an encapsulated juice powder concentrate might affect several measures of vascular health was tested in free living adults at low cardiovascular risk. Blood pressure, vascular compliance, lipid and antioxidant markers, and serial electron beam tomography (to calculate a coronary artery calcium score as a measure of atherosclerosis burden), were monitored in 51 prehypertensive and hypertensive subjects over 2 years. By the end of follow-up, systolic and diastolic blood pressure decreased significantly $(-2.4 \pm 1.0 \mathrm{mmHg}, \quad P<0.05$ and $-2.2 \pm 0.6 \mathrm{mmHg}, \quad P<0.001), \quad$ and large artery compliance improved significantly $\left(1.9 \pm 0.6 \mathrm{ml} \mathrm{mmHg}^{-1} \times 100, P<0.01\right)$. The progression of coronary artery calcium score was smaller than expected compared with a historical database $(P<0.001)$. Laboratory testing showed a significant decrease in homocysteine $(P=0.05)$, HDL cholesterol $(P=0.025)$ and Apo A $(P=0.004)$, as well as a significant increase in $\beta$-carotene, folate, Co-Q10 and $\alpha$-tocopherol (all $P<0.001$ ). The phytonutrient concentrate we utilized induced several favorable modifications of markers of vascular health in the subjects. This study supports the notion that plant nutrients are important components of a heart healthy diet.
\end{abstract}

Keywords: antioxidant - blood pressure - coronary artery calcium - fruit - hypertension vegetable

\section{Introduction}

The protective effects of fruits and vegetables against coronary heart disease and myocardial infarction have been reported in numerous populations worldwide (1-5). In observational studies, antioxidant vitamins, associated with an increased dietary intake of fruits and vegetables, have been inversely associated with cardiovascular disease and all-cause mortality (6-8). Despite theoretical

For reprints and all correspondence: Paolo Raggi, MD, 1365 Clifton Road NE, AT-504, Atlanta, Georgia 30322, USA. Tel: (404) 778-5567; Fax: (404) 778-3540; E-mail: praggi@excite.com advantages, supportive laboratory and epidemiological evidence, randomized clinical trials of selected antioxidant vitamins (A, C, E) and selenium have produced conflicting results related to coronary heart disease and cardiovascular disease (9-15). Of interest, some cultures rely heavily on the effect of herbal medicines for control of hyperlipidemia, hypertension and other ailments (16). Currently, both the American Heart Association Science Advisory Council and the American College of Cardiology do not recommend the use of single antioxidant vitamin supplements for cardiovascular prevention; nonetheless, these organizations do recommend the consumption of a diet high in sources of antioxidants 
and other nutrients such as fruits, vegetables, whole grains and nuts to reduce the risk of cardiovascular disease $(17,18)$.

This prospective pilot study was undertaken to evaluate the effect of a proprietary encapsulated juice powder concentrate, made primarily of multiple fruits, vegetables and berries on several surrogate markers of cardiovascular health and risk in asymptomatic adults. Assessed were: progression of coronary artery calcium score, a sensitive marker of atherosclerosis; systemic and diastolic blood pressure; arterial compliance; markers of antioxidant status and serum lipid levels in patients taking the phytonutrient preparation for 2 years.

\section{Methods}

\section{Subjects}

This 24-month prospective pilot study was approved by the local Institutional Review Board. Informed consent was obtained from 54 ambulatory patients (44 men) between the ages of 40 and 75 years asymptomatic for coronary heart disease. Subjects were recruited from the Hypertension Institute and the Saint Thomas Medical Group practices in Nashville, TN, USA. All subjects were asymptomatic for coronary heart disease (no clinical history of angina, myocardial infarction, coronary revascularization) and had a coronary artery calcium score at enrollment between 30 and 400. The lower coronary artery calcium score threshold was chosen based on published evidence demonstrating better reproducibility beyond this limit (19). A coronary artery calcium score $>400$ has been shown to be associated with a high risk of obstructive coronary artery disease and cardiac events and it was therefore decided a priori to exclude such high risk patients. Further inclusion criteria included baseline fasting LDL cholesterol $<4.92 \mathrm{mmoll}^{-1}$ and triglycerides $<4.52 \mathrm{mmoll}^{-1}$, and two or fewer risk factors for coronary heart disease. Exclusion criteria included symptomatic angina or known coronary heart disease, single vessel coronary artery stenosis over $50 \%$ or left main artery stenosis over $30 \%$. Additional exclusion criteria were use of any lipid lowering therapy, concomitant use of any antioxidant, vitamin, nutritional or nutraceutical supplements and women of childbearing potential.

After enrollment, no changes were allowed in antihypertensive medications, other prescription drugs or aspirin during the study period. No dietary or activity instructions were given, rather participants were asked to maintain their habitual diet, exercise program, tobacco utilization, alcohol intake and other lifestyle behaviors. Subjects underwent follow-up visits at 4-month intervals.

\section{Imaging, Vascular Compliance, Blood Pressure Measurements and Laboratory Testing}

All patients underwent imaging with electron beam tomography 3 times: at baseline, 12 and 24 months (though these time points were not tightly monitored and some patients underwent the repeat scans at slightly different times but no more than a week or two from the planned time). All electron beam tomography scans were performed utilizing a C-150 scanner (Imatron/GE, San Francisco, CA, USA) according to a standardized protocol. In brief: 40 to 50 tomographic sections with a single slice thickness of $3 \mathrm{~mm}$ were obtained during a single breath holding period. Scanning was electrocardiographically triggered at $60-80 \%$ of the $\mathrm{R}-\mathrm{R}$ interval on the surface electrocardiogram and imaging began at the level of the bronchial carina and extended to the level of the diaphragm. All areas of calcification with a minimal computed tomography attenuation of 130 Hounsfield Units seen within the borders of the coronary arteries were computed. A calcified plaque was considered present if at least three contiguous pixels with a density of 130 Hounsfield Units or greater were detected. All images were reviewed on a NetraMD workstation (ScImage, Los Altos,CA, USA).

Scans were considered of acceptable research quality only if the images were free from motion or metal artifacts. All scans were read blindly by one (BJO) experienced investigator for consistency. A coronary artery calcium score for each area of interest was calculated as originally described by Agatston et al. (20). This scoring method incorporates the density and volume of a calcified plaque, therefore a score increase may be due to either plaque enlargement or increased density or both. The reverse would be true for a score decrease. Total calcium scores were calculated as the sum of all individual coronary artery scores. The published median inter-scan coronary artery calcium score variability for the Agatston score is $8-10 \%$ (21). The total radiation dose absorbed by each patient from the three scans was of $\sim 1.5 \mathrm{mSievert}$ (the maximum recommended yearly dose is $5 \mathrm{mSv}$ for nonmedical personnel in the US).

The CV Profiler-HDI CR-2000 (Hypertension Diagnostics Incorporated, Eagan, Minnesota) was utilized for assessment of arterial wave forms and small vessel as well as large vessel arterial compliance. Compliance is measured as the change in vessel diameter and volume per each $\mathrm{mmHg}$ of pressure change $\left(\mathrm{ml} / \mathrm{mmHg}^{-1} \times 100\right)$. Arterial compliance was measured at baseline, 12 and 24 months.

Baseline history, physical exam, blood pressure, weight, and heart rate measurements were repeated every 4 months for 24 months. Blood pressure was recorded as the average of two manual measurements and three automated measurements, taken after the subject lay in a supine position for $15 \mathrm{~min}$. Laboratory tests for 
$\beta$-carotene, $\alpha$-tocopherol, folate, Co-Q10, vitamin C, glycated hemoglobin and a lipid profile were performed by a commercial diagnostic laboratory (Kronos Science Laboratories, Inc., Phoenix, AZ, USA). Blood samples were collected at baseline, 4 months and 24 months.

\section{Nutritional Intervention}

Subjects were instructed to take three capsules of the phytonutrient preparation twice daily with meals. Compliance with study protocol was determined by review of patient diaries and investigators' pill count at each visit, and averaged $85 \%$ or better during the followup period. The phytonutrient preparation (Juice Plus $+{ }^{\circledR}$, NSA, Inc., Memphis,TN, USA) is an encapsulated juice powder concentrate blend consisting primarily of fruits, vegetables and berries including: acerola cherry, apple, beet, bilberry, blackberry, black currant, blueberry, broccoli, cabbage, carrot, cranberry, Concord grape, elderberry, kale, orange, papaya, parsley, peach, pineapple, raspberry, red currant, spinach and tomato. Six capsules daily provided $\sim 7.5 \mathrm{mg} \beta$-carotene, $276 \mathrm{mg}$ vitamin $\mathrm{C}, \quad 71 \mathrm{mg}$ vitamin $\mathrm{E}$ and $780 \mathrm{mcg}$ folate and about $63 \mathrm{~kJ}$. Other than minor gastrointestinal complaints early in the study, there were no reports of adverse effects attributed to the phytonutrient preparation over the 24 months of follow-up.

\section{Statistical Analyses}

Of the 54 subjects entering the investigation, three withdrew before the first follow-up visit. One woman withdrew due to the prescription of a medication excluded from the study and two men due to gastrointestinal distress possibly due to the phytonutrient preparation. The remaining 51 subjects contributed data. One man withdrew consent after the 4-month follow-up visit, one man withdrew consent after the 8-month follow-up visit, three subjects (one woman, two men) withdrew consent after the 12-month follow-up visit and one man withdrew from the study due to prescription of an excluded medication. These six subjects are included in the data until the time of their withdrawal. Hence, comparisons were made only between patients who had baseline assessments and remained in the study at each analysis point.

Annualized change and relative annualized change were calculated for each patient at 1- and 2-year intervals for blood pressure values, weight, arterial compliance values, coronary artery calcium score values (absolute scores and percentiles) and blood chemistries. Coronary artery calcium score percentiles were calculated as the proportion of patients with coronary calcium in predefined and non-overriding age groups from a database of 10122 asymptomatic patients (22). The annualized rates of absolute change and relative change in coronary artery calcium score were compared to changes recorded in historical untreated controls of 29.7 and $34.7 \%$, respectively, (23) using one-sample $t$-tests. In general, changes were annualized for primarily two reasons: patients did not return for follow-up visits at precise 12-month intervals, and annualization facilitates the comparison between changes at intervals of 12 and 24 months (Table 1). Annualization was also important when analyzing coronary artery calcium score values because comparative historical data were only available in annualized format.

In each case, the paired $t$-statistic was used to construct confidence intervals and to test for significant annualized changes between baseline and follow-up among all patients first and pre-hypertensive and hypertensive patients later. The one-sample Wilcoxon test on medians was used to confirm significance in this case. Welch's $t$-test was used to compare all baseline values of prehypertensive and hypertensive patients, and significant results were confirmed using the Mann-Whitney rank sum test. Best-subsets regression was used to study how age, sex, hypertension, and baseline body weight, arterial compliance values and coronary calcium measures were related to the annualized changes over 2 years in systemic blood pressure, arterial compliance and coronary calcium

Table 1. Annualized changes at 12- and 24-month follow-up for coronary artery calcium scores, arterial compliance, and blood pressure, with values expressed as mean $\pm \mathrm{SEM}$ (median, range)

\begin{tabular}{lrr}
\hline Variable & \multicolumn{1}{l}{ Full cohort } \\
\cline { 2 - 3 } & \multicolumn{1}{l}{ 12-Month } & $24-$ Month \\
\hline Calcium score & $26 \pm 6.3^{* * * *}(18,204)^{* * *}$ & $17 \pm 3.2^{* * *}(14,108)^{* * *}$ \\
Relative calcium score & $26 \pm 6.2^{* * *}(22,213)^{* * *}$ & $20 \pm 4.0^{* * *}(20,167)^{* * *}$ \\
Calcium score percentile & $1.3 \pm 1.1(2.8,42)^{*}$ & $1.1 \pm 0.6(1.7,22)^{*}$ \\
Small artery compliance $\left(\mathrm{ml} \mathrm{mmHg}{ }^{-1} \times 100\right)$ & $0.34 \pm 0.43(0.00,17.1)$ & $-0.14 \pm 0.21(-0.30,6.5)$ \\
Large artery compliance $\left(\mathrm{ml} \mathrm{mmHg}{ }^{-1} \times 100\right)$ & $1.5 \pm 1.3(0.4,47)$ & $1.9 \pm 0.6^{* *}(1.5,17)^{* *}$ \\
Systolic blood pressure $(\mathrm{mmHg})$ & $-3.0 \pm 2.0(-1.4,74)$ & $-2.4 \pm 1.0^{*}(-1.5,27)^{*}$ \\
Diastolic blood pressure $(\mathrm{mmHg})$ & $-3.0 \pm 1.0^{* *}(-2.8,27)^{* *}$ & $-2.2 \pm 0.61^{* * *}(-2.0,16)^{* *}$ \\
\hline
\end{tabular}

$* P<0.05 ; * * P<0.01 ; * * * P<0.001$ (relative to baseline) by paired $t$-test (and Wilcoxon one-sample test).

${ }^{a}$ Calcium score comparisons with historical 29.7-point annual change: these are significant relative to annualized 24-month change for full cohort $(P<0.001)$, 24-month change for pre-hypertensives $(P<0.01)$ and 24 -month change for hypertensives $(P<0.05)$; it is not significantly different from the 12-month change in the full cohort. 
measurements. The best models were chosen as those that minimized the Bayesian Information Criterion (BIC) subject to the constraint that the ratio of observations to parameters exceeded 5, but this ratio actually exceeded 10 for all selected models. The BIC has been shown to be a consistent criterion in very general theoretical settings and to provide models that perform well in empirical studies.

\section{Results}

\section{Baseline Characteristics and Change in Coronary Artery Calcium Score}

The baseline clinical characteristics of all patients enrolled in the study are shown in Table 2. Most of the study subjects were hypertensive $(n=38)$, although some were classified as pre-hypertensive $(n=13)$. The majority were men $(80 \%)$ and the mean age was
$61 \pm 6.5$ years. Table 1 shows the mean annualized changes (measured change divided by number of months of observation and multiplied by 12) at 12 and 24 months of follow-up for coronary artery calcium scores, arterial compliance and blood pressure. The annualized change in absolute coronary artery calcium score was $26 \pm 6$ points at 12 months $(P<0.001$ from baseline $)$ and $17 \pm 3.2$ points at 24 months $(P<0.001$ from baseline). These values corresponded to a relative change of $26 \pm 6$ and $20 \pm 4 \%$, respectively from baseline $(P<0.001$ in each case). In comparison, the annualized change in absolute and relative coronary artery calcium score in historical untreated controls were 29.7 and $34.7 \%$, respectively (23) $(P<0.001$ for each, one-sample $t$-tests $)$.

\section{Change in Arterial Blood Pressure and Compliance}

Figure 1 shows the change over time in systolic blood pressure and Fig. 2 shows the change over time in

Table 2. Baseline clinical characteristics

\begin{tabular}{|c|c|c|c|}
\hline Clinical characteristics & Full cohort & Pre-hypertensive subjects & Hypertensive subjects \\
\hline Sample size & 51 & 13 & 38 \\
\hline Men $(\%)$ & 80 & 69 & 84 \\
\hline Diabetes mellitus (\%) & 4 & 0 & 5 \\
\hline Smoking $(\%)$ & 6 & 0 & 8 \\
\hline Hypertension (\%) & 75 & - & 100 \\
\hline Age (years) & $61 \pm 6.5(61,28)$ & $59 \pm 6.6(58,26)$ & $62 \pm 6.4(62,26)$ \\
\hline Systolic blood pressure $(\mathrm{mmHg})$ & $134 \pm 18(129,74)$ & $120 \pm 14(115,44)$ & $139 \pm 17^{* * *}(135,60)^{* * *}$ \\
\hline Diastolic blood pressure $(\mathrm{mmHg})$ & $82 \pm 9.3(82,40)$ & $76 \pm 7.5(74,25)$ & $85 \pm 9.0^{* *}(84,35)^{* *}$ \\
\hline Weight (kg) & $91 \pm 15(88,73)$ & $86 \pm 14.5(88,50)$ & $92 \pm 16(90,60)$ \\
\hline Small artery compliance $\left(\mathrm{ml} \mathrm{mmHg}^{-1} \times 100\right)$ & $5.3 \pm 2.7(4.5,10)$ & $6.6 \pm 2.4(6.6,7.2)$ & $4.8 \pm 2.7^{*}(4.1,10)^{*}$ \\
\hline Total cholesterol $\left(\mathrm{mmoll}^{-1}\right)$ & $5.33 \pm 0.79(5.33,3.36)$ & $5.64 \pm 0.86(5.87,2.64)$ & $5.22 \pm 0.74(5.18,3.36)$ \\
\hline HDL cholesterol $\left(\mathrm{mmoll}^{-1}\right)$ & $1.20 \pm 0.39(1.11,1.84)$ & $1.21 \pm 0.37(1.11,1.45)$ & $1.19 \pm 0.40(1.06,1.84)$ \\
\hline LDL cholesterol $\left(\mathrm{mmoll}^{-1}\right)$ & $3.45 \pm 0.64(3.57,2.97)$ & $3.61 \pm 0.75(3.83,2.59)$ & $3.40 \pm 0.60(3.54,2.66)$ \\
\hline Triglycerides $\left(\mathrm{mmoll}^{-1}\right)$ & $1.42 \pm 0.68(1.23,3.04)$ & $1.67 \pm 0.71(1.40,2.28)$ & $1.34 \pm 0.66(1.18,3.04)$ \\
\hline Apo $\mathrm{A}\left(\mathrm{gl}^{-1}\right)$ & $1.41 \pm 0.30(1.32,1.68)$ & $1.42 \pm 0.25(1.44,0.97)$ & $1.41 \pm 0.32(1.32,1.68)$ \\
\hline Apo B $\left(\mathrm{gl}^{-1}\right)$ & $1.10 \pm 0.17(1.09,0.70)$ & $1.14 \pm 0.20(1.13,0.66)$ & $1.08 \pm 0.15(1.07,0.69)$ \\
\hline Glycosylated hemoglobin, proportion of total hemoglobin & $0.055 \pm 0.008(0.056,0.050)$ & $0.052 \pm 0.006(0.055,0.019)$ & $0.057 \pm 0.008(0.057,0.050)$ \\
\hline Homocysteine $\left(\mu \mathrm{moll}^{-1}\right)$ & $10.4 \pm 2.3(10.2,10.7)$ & $10.5 \pm 2.5(9.8,8.3)$ & $10.3 \pm 2.2(10.2,10.0)$ \\
\hline Vitamin $\mathrm{C}\left(\mu \mathrm{moll}^{-1}\right)$ & $675 \pm 195(650,761)$ & $776 \pm 216(715,647)$ & $640 \pm 177(619,727)$ \\
\hline
\end{tabular}

Values expressed as percentages, mean $\pm \mathrm{SD}$, and median and range where appropriate.

The $P$-values refer to comparisons between pre-hypertensive and hypertensive patients: $* P<0.05$; $* * P<0.01 ; * * * P<0.001$ by Welch's $t$-test (and Mann-Whitney rank sum test). 
diastolic blood pressure from baseline, at each of the six follow-up visits. Both measures decreased significantly in the full cohort at the end of 2 years of follow-up compared with baseline (systolic $-2.4 \pm 1.0 \mathrm{mmHg}$, $P<0.05$ and diastolic $-2.2 \pm 0.6 \mathrm{mmHg}, P<0.001)$ in the absence of any modification in anti-hypertensive therapy. Large artery compliance improved significantly $\left(1.9 \pm 0.6 \mathrm{ml} \mathrm{mmHg}^{-1} \times 100, P<0.01\right)$, while small artery compliance showed a slight but non-significant decrease.

\section{Changes in Serological Values}

Table 3 shows that compared with baseline, at the end of 24 months of follow-up there was a significant

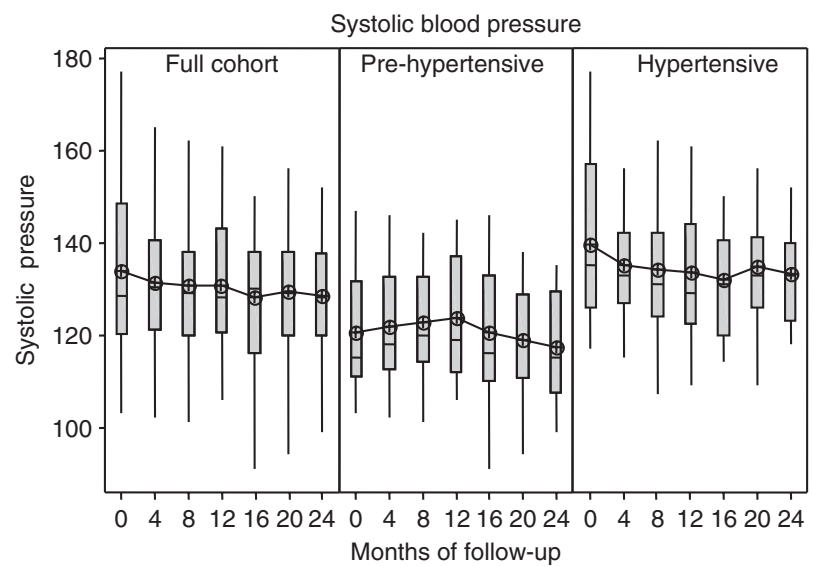

Figure 1. Systolic blood pressure change over time, shown by full cohort and the hypertensive and pre-hypertensive subgroups, with each box plot showing the distribution of subject values for recorded systolic blood pressure measured at baseline and 4-month intervals for six follow-up visits. The means of each distribution are connected across periods.

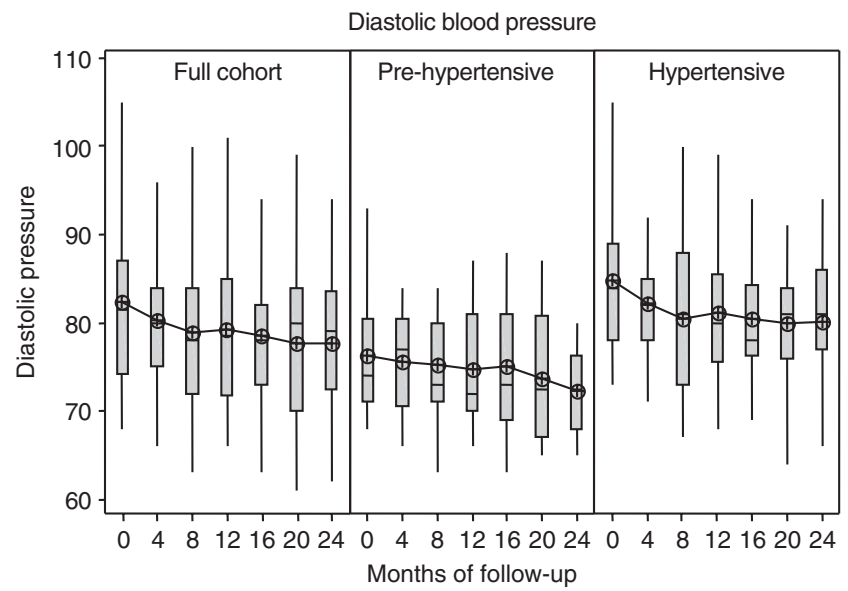

Figure 2. Diastolic blood pressure change over time, shown by full cohort and the hypertensive and pre-hypertensive subgroups, with each box plot showing the distribution of subject values for recorded diastolic blood pressure measured at baseline and 4-month intervals for six follow-up visits. The means of each distribution are connected across periods. decrease in homocysteine $(P<0.05)$, HDL cholesterol $(P=0.025)$ and Apo A $(P=0.004)$. Additionally, a significant increase was seen in $\beta$-carotene, folate, Co-Q10 and $\alpha$-tocopherol (all $P<0.001$ ). Finally, glycosylated hemoglobin showed a borderline significant decrease $(P=0.059)$, and LDL cholesterol a borderline significant increase $(P=0.062)$.

\section{Regression Analyses}

Table 4 summarizes the best models for all significant 2-year changes (Table 1) in systemic blood pressure, arterial compliance and coronary calcium measurements. The baseline values of these variables, along with age, sex, and baseline weight, were considered as candidate predictors. Hypertension is significant in models for both change and relative change in calcium score, and baseline systolic blood pressure is the pre-eminent predictor in both models for change in systemic blood pressure.

\section{Discussion}

Our main findings could be summarized as follows: the mean calcium score changes at the end of follow-up in this group were statistically smaller than the changes recorded in an historical population (29.7 and 34.7\%, respectively, $P<0.001$ in each case). In addition, these pilot study subjects also had reduced systemic blood pressure in the presence of stable anti-hypertensive therapy and improved vascular compliance of large arteries in the absence of change in body weight (data not shown). The above changes were concurrent with an improvement in markers of antioxidant status, homocysteine and glycosylated hemoglobin.

These data may provide a rationale for the observed reduced incidence of coronary heart disease in vegetarians, who demonstrate a 3-5 year overall longer survival compared to omnivores. The European Prospective Investigation into Cancer and Nutrition-Oxford study of 56000 British men and women demonstrated a reduced risk for coronary heart disease in vegetarians (24). In several observational studies components of a plant-based diet, such as phytochemicals (25), fiber (26), nuts (27) and whole grain cereals (28), have been shown to reduce the risk for coronary heart disease. Furthermore, vegetarian diets, coupled with intense life style changes, have resulted in angiographic improvement of obstructive coronary artery disease (29). Multiple studies have suggested that an optimal intake of fruits, vegetables, whole grains and fiber may provide a variety of cardio-protective nutrients and non-nutrient factors with improvement in endothelial function, blood pressure, serum lipid levels, glucose, homocysteine, weight, body fat and reduction in oxidative stress and vascular inflammation (30-34). It has been suggested 
Table 3. Baseline and annualized 24-month change in lipids and other blood values expressed as mean $\pm \mathrm{SD}$

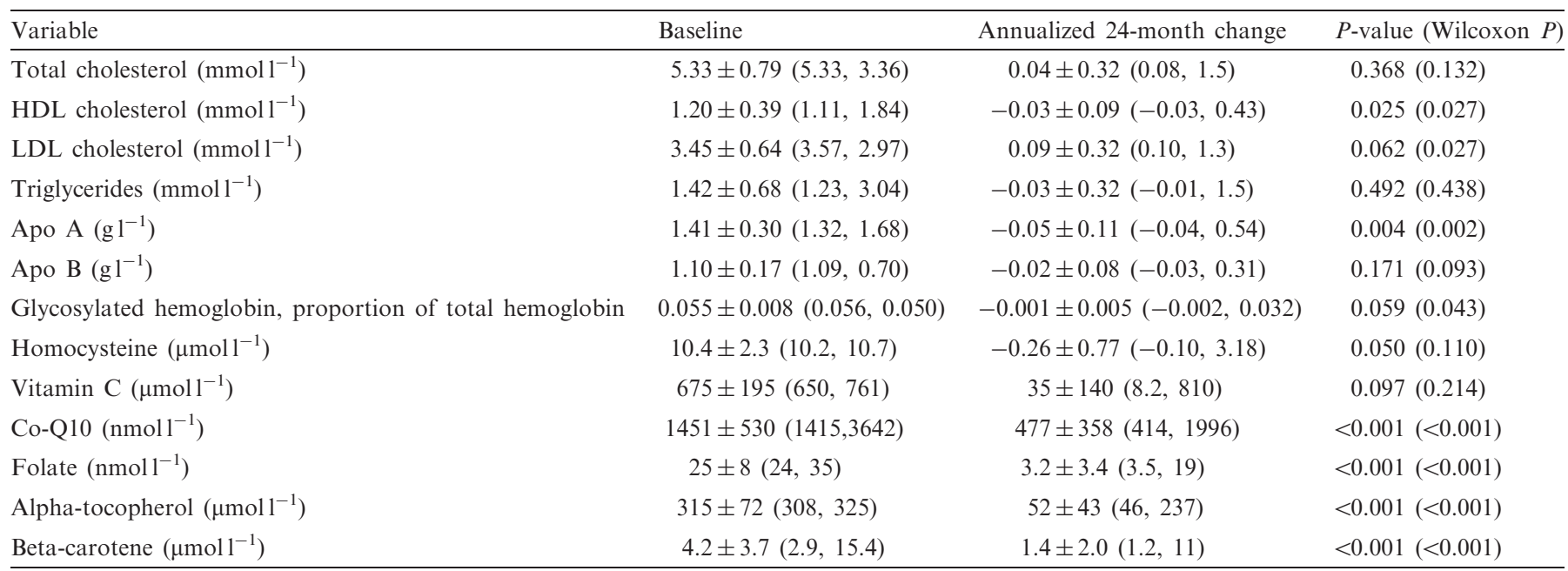

Table 4. Best models for variables of Table 1 that changed significantly over 24 months in terms of baseline values (for all Table 1 variables, along with sex, weight, and hypertension)

\begin{tabular}{|c|c|c|c|c|}
\hline Dependent ( $R$-square) 24-month annualized change in: & Predictor from baseline & Coefficient (SE) & $P$-value & Univariate $P$-value \\
\hline \multicolumn{5}{|l|}{ Calcium score $(34 \%)$} \\
\hline & Constant & $-11.9(6.65)$ & 0.082 & \\
\hline & Calcium score & $0.187(0.0424)$ & 0.000 & 0.001 \\
\hline \multicolumn{5}{|l|}{ Calcium relative change $(9 \%)$} \\
\hline & No constant ${ }^{\mathrm{a}}$ & & & \\
\hline \multicolumn{5}{|l|}{ Large artery compliance $(8 \%)$} \\
\hline & Constant & $5.378(1.77)$ & 0.004 & \\
\hline & Large artery $\mathrm{C}$ & $-0.242(0.118)$ & 0.046 & 0.046 \\
\hline \multicolumn{5}{|l|}{ Systolic blood pressure $(53 \%)$} \\
\hline & Constant & $24.2(5.35)$ & 0.000 & \\
\hline & Constant & $9.34(4.50)$ & 0.047 & \\
\hline & Weight & $0.0284(0.0133)$ & 0.042 & 0.059 \\
\hline & Systolic & $-0.131(0.0246)$ & 0.000 & $<0.001$ \\
\hline
\end{tabular}

${ }^{\mathrm{a}}$ When a constant is added to this model its coefficient is larger than its standard error. In each case, the direction of univariate association is the same as the sign of multivariate coefficient.

that a plausible explanation for such favorable effects may be a nutrient-gene interaction that contributes to a reduction in coronary heart disease.

Coronary artery calcification is an excellent marker of atherosclerosis and its presence is associated with a substantially increased risk of cardiac events (35-38). Some investigators have suggested modifying the calculated Framingham Risk Score with data derived from calcium screening, thereby increasing or decreasing the estimated risk of an event $(39,40)$. Calcium screening could be particularly helpful in patients at intermediate risk of events (36) where the presence of calcium increases (and its absence decreases) the probability of an event. In this light, a middle-aged man with hypertension (as most of the patients in our study) may benefit from calcium screening for more accurate risk stratification. Recently, sequential coronary artery calcium scoring has been used to monitor the progression of atherosclerosis in adults treated with lipid-lowering agents (38), phosphate binding agents in renal failure (41) as well as nutritional 
supplements (42). Of note, progression of coronary artery calcium score has been shown to be associated with a significant increase in risk of cardiovascular events $(23,38)$. Hence, slowing of coronary artery calcium score progression appears to be a worthy goal of therapy. Importantly, the best predictor of coronary artery calcium score progression in this study was hypertension, suggesting the very significant role played by this risk factor in progression of atherosclerosis.

Abnormal arterial compliance, an accurate marker of vascular stiffness, has been shown to be associated with aging, multiple cardiovascular risk factors and with an adverse cardiovascular outcome (43). Improvement in arterial compliance in this pilot study is further evidence of the potentially favorable effects of fruits and vegetables on the overall vascular health of an individual.

While the importance of antioxidants in the reduction of cardiovascular disease remains controversial, the parallel reduction of oxidative stress and other markers of vascular damage are reassuring. In this light, it is intriguing that a powder concentrate containing numerous phytonutrients, as opposed to tablets of single vitamins, was sufficient to attain the favorable surrogate results demonstrated.

We have no biologically plausible explanation for Juice Plus+ alone (in the absence of a change in weight as discussed earlier) to have any impact on cholesterol lipoprotein concentrations. Juice Plus+ has been shown to impact LDL cholesterol oxidation, but not total amount of LDL cholesterol and no effect on HDL has ever been demonstrated. Even though a diet high in fruits, vegetables and whole grains is beneficial regarding lipoprotein concentrations, this effect is largely attributed to the fiber components of these foods. When cholesterol was monitored more closely, as in the study by Plotnick et al. (44), no consistent effect was noted. In observational studies a reduction, and not an increase, in LDL cholesterol has been associated with lack of progression of coronary artery calcium (45), while there has been no study so far of the effect of HDL level modification on coronary calcium. Hence, one would have expected a negative effect on calcium progression from the observed changes in cholesterol lipoprotein but this did not occur. To further investigate this issue, we searched the human medical literature for evidence that $\beta$-carotene or vitamin E may impact lipid concentrations, but found no evidence for such an effect.

Limitations of this pilot study included the small sample size and lack of a placebo group. The comparison of change in coronary artery calcium score compared to the historical database is not optimal because of temporal differences of when that data were collected, along with other potential differences between this study population and the contributors to the database information. In addition, although some investigators have raised concerns about the reliability of the CR-2000 used to assess arterial compliance (42), others have disputed this opinion and finding the CR-2000 highly reproducible (46).

In summary, this pilot study showed a favorable effect of an encapsulated juice powder concentrate, made primarily of multiple fruits, vegetables and berries, on several surrogate markers of cardiovascular disease. Additional placebo-controlled prospective studies will be required to confirm these findings.

\section{Acknowledgements}

This work was supported in part by the Dean's Fund for Faculty Research, Owen Graduate School of Management, Vanderbilt University, Nashville, TN and by a grant from NSA, Inc., Memphis, TN, USA.

\section{References}

1. Hirvonen T, Pietinen P, Virtanen M, Ovaskainen ML, Hakkinen S, Albanes D, et al. Intake of flavonols and flavones and risk of coronary heart disease in male smokers. Epidemiology 2001; $12: 62-67$.

2. Hertog MG, Feskens EJ, Hollman PC, Katan MB, Kromhout D. Dietary antioxidant flavonoids and risk of coronary heart disease: The Zutphen Elderly Study. Lancet 1993;342:1007-11.

3. Sasazuki S, Fukuoka Heart Study Group. Case-control study of nonfatal myocardial infarction in relation to selected foods in Japanese men and women. Jpn Circ J 2001;65:200-6.

4. Law MR, Morris JK. By how much does fruit and vegetable consumption reduce the risk of ischaemic heart disease? Eur J Clin Nutr 1998;52:549-56.

5. Joshipura KJ, Hu FB, Manson JE, Stampfer MJ, Rimm EB, Speizer FE, et al. The effect of fruit and vegetable intake on risk for coronary heart disease. Ann Intern Med 2001;134:1106-14.

6. Rimm EB, Stampfer MJ, Ascherio A, Giovannucci E, Colditz GA, Willett WC. Vitamin E consumption and the risk of coronary heart disease in men. $N$ Engl J Med 1993;328:1450-6.

7. Stampfer MJ, Hennekens CH, Manson JE, Colditz GA, Rosner B, Willett WC. Vitamin E consumption and the risk of coronary heart disease in women. N Engl J Med 1993;328:1444-9.

8. Salonen RM, Nyyssonen K, Kaikkonen J, Porkkala-Sarataho E, Voutilainen S, Rissanen TH, et al. Six year effect of combined vitamin $\mathrm{C}$ and $\mathrm{E}$ supplementation on atherosclerotic progression: the Antioxidant Supplementation in Atherosclerosis Prevention (ASAP) study. Circulation 2003;107:947-53.

9. Stephens NG, Parsons A, Schofield PM, Kelly F, Cheeseman K, Mitchinson MJ. Randomised controlled trial of vitamin E in patients with coronary disease: Cambridge Heart Antioxidant Study (CHAOS). Lancet 1996;347:781-6.

10. Boaz M, Smetana S, Weinstein T, Matas Z, Gafter U, Iaina A, et al. Secondary prevention with antioxidants of cardiovascular disease in end-stage renal disease (SPACE): Randomised placebocontrolled trial. Lancet 2000;356:1213-8.

11. GISSI-Prevenzione Investigators. Dietary supplementation with $n-3$ polyunsaturated fatty acids and vitamin $\mathrm{E}$ after myocardial infarction: Results of the GISSI-Prevenzione trial. Lancet 1999; 354:447-55.

12. Yusuf S, Dagenais G, Pogue J, Bosch J, Sleight P. Vitamin E supplementation and cardiovascular events in high-risk patients. The Heart Outcomes Prevention Evaluation Study Investigators. $N$ Engl J Med 2000;342:154-60.

13. Heart Protection Study Collaborative Group. MRC/BHF Heart Protection Study of antioxidant vitamin supplementation in 20,536 high-risk individuals: a randomised placebo-controlled trial. Lancet 2002;360:23-33, doi:10.1016/S0140-6736(02)09328-5.

14. Hodis HN, Mack WJ, LaBree L, Mahrer PR, Sevanian A, Liu CR, et al. Alpha-tocopherol supplementation in healthy individuals 
reduces low-density lipoprotein oxidation but not atherosclerosis: the Vitamin E Atherosclerosis Prevention Study (VEAPS). Circulation 2002;106:1453-9.

15. Rapola JM, Virtamo J, Ripatti S, Huttunen JK, Albanes D, Taylor PR, et al. Randomised trial of alpha-tocopherol and betacarotene supplements on incidence of major coronary events in men with previous myocardial infarction. Lancet 1997;349:1715-20.

16. Azaizeh H, Saad B, Khalil K, Said O. The state of the art of traditional Arab herbal medicine in the Eastern region of the Mediterranean: A review. Evid Based Complement Alternat Med 2006:3:229-35.

17. Gibbons RJ, Abrams J, Chatterjee K, Daley J, Deedwania PC, Douglas JS, et al. ACC/AHA 2002 guideline update for the management of patients with chronic stable angina - summary article: a report of the American College of Cardiology/American Heart Association Task Force on Practice Guidelines (Committee on the Management of Patients with Chronic Stable Angina). Circulation 2003;107:149-58.

18. Mosca L, Appel LJ, Benjamin EJ, Berra K, Chandra-Strobos N, Fabunmi RP, et al. Evidence-based guidelines for cardiovascular disease prevention in women. Circulation 2004;109:672-93.

19. Callister TQ, Cooil B, Raya SP, Lippolis NJ, Russo DJ, Raggi P. Coronary artery disease: improved reproducibility of calcium scoring with an electron-beam CT volumetric method. Radiology 1998;208:807-14.

20. Agatston AS, Janowitz WR, Hildner FJ, Zusmer NR, Viamonte M Jr, Detrano R. Quantification of coronary artery calcium using ultrafast computed tomography. J Am Coll Cardiol 1990;15:827-32.

21. Achenbach S, Ropers D, Mohlenkamp S, Schmermund A, Muschiol G, Groth J, et al. Variability of repeated coronary artery calcium measurements by electron beam tomography. Am J Cardiol 2001;87:210-3.

22. Raggi P, Callister TQ, Cooil B, He ZX, Lippolis NJ, Russo DJ, et al. Identification of patients at increased risk of first unheralded acute myocardial infarction by electron-beam computed tomography. Circulation 2000;101:850-5.

23. Raggi P, Cooil B, Shaw LJ, Aboulhson J, Takasu J, Budoff M, et al. Progression of coronary calcium on serial electron beam tomographic scanning is greater in patients with future myocardial infarction. Am J Cardiol 2003;92:827-9.

24. Key TJ, Appleby PN, Davey GK, Allen NE, Spencer EA, Travis RC. Mortality in British vegetarians: review and preliminary results from EPIC-Oxford. Am J Clin Nutr 2003;78:533S-8S.

25. Most MM. Estimated phytochemical content of the Dietary Approaches to Stop Hypertension (DASH) diet is higher than in the control study diet. J Am Diet Assoc 2004;104:1725-7.

26. Pereira MA, O'Reilly E, Augustsson K, Fraser GE, Goldbourt U, Heitmann BL, et al. Dietary fiber and risk of coronary heart disease: a pooled analysis of cohort studies. Arch Intern Med 2004; 164:370-6.

27. Hu FB, Stampfer MJ, Manson JE, Rimm EB, Colditz GA, Rosner BA, et al. Frequent nut consumption and risk of coronary heart disease in women: prospective cohort study. BMJ 1998; 317:1341-5.

28. Liu S, Stampfer MJ, Hu FB, Giovannucci E, Rimm E, Manson JE, et al. Whole-grain consumption and risk of coronary heart disease: results from the Nurses' Health Study. Am J Clin Nutr 1999; 70:412-9.

29. Ornish D, Scherwitz LW, Billings JH, Brown SE, Gould KL, Merritt TA, et al. Intensive lifestyle changes for reversal of coronary heart disease. JAMA 1998;280:2001-7.

30. Gardner CD, Coulston A, Chatterjee L, Rigby A, Spiller G, Farquhar JW. The effect of a plant-based diet on plasma lipids in hypercholesterolemic adults: a randomized trial. Ann Intern Med 2005; 142:725-33.

31. Dragsted LO, Pedersen A, Hermetter A, Basu S, Hansen M, Haren GR, et al. The 6-a-day study: Effects of fruit and vegetables on markers of oxidative stress and antioxidative defense in healthy nonsmokers. Am J Clin Nutr 2004;79:1060-72.

32. Gao X, Bermudez OI, Tucker KL. Plasma C-reactive protein and homocysteine concentrations are related to frequent fruit and vegetable intake in Hispanic and non-Hispanic white elders. J Nutr 2004;134:913-8.

33. Ros E, Nunez I, Perez-Heras A, Serra M, Gilabert R, Casals E, et al. A walnut diet improves endothelial function in hypercholesterolemic subjects: a randomized crossover trial. Circulation 2004;109:1609-14.

34. Lopez-Garcia E, Schulze MB, Manson JE, Meigs JB, Albert CM, Rifai N, et al. Consumption of (n-3) fatty acids is related to plasma biomarkers of inflammation and endothelial activation in women. J Nutr 2004;134:1806-11.

35. Raggi P, James G. Coronary calcium screening and coronary risk stratification. Curr Atheroscler Rep 2004;6:107-11.

36. Pletcher MJ, Tice JA, Pignone M, Browner WS. Using the coronary artery calcium score to predict coronary heart disease events: a systemic review and meta-analysis. Arch Intern Med 2004; 164:1285-92

37. Greenland P, LaBree L, Azen SP, Doherty TM, Detrano RC. Coronary artery calcium score combined with Framingham score for risk prediction in asymptomatic individuals. JAMA 2004; 291:210-5.

38. Raggi P, Cooil B, Ratti C, Callister TQ, Budoff M. Progression of coronary artery calcium and occurrence of myocardial infarction in patients with and without diabetes mellitus. Hypertension 2005; 46:238-43.

39. Grundy SM. Cholesterol management in the era of managed care. Am J Cardiol 2000;85:3A-9A.

40. Schisterman EF, Whitcomb BW. Coronary age as a risk factor in the modified Framingham risk score. BMC Med Imaging 2004:4:1.

41. Chertow GM, Burke SK, Raggi P. Treat to Goal Working Group: Sevelamer attenuates the progression of coronary and aortic calcification in hemodialysis patients. Kidney Int 2002;62:245-52.

42. Rath M, Niedzwiecki A. Nutritional supplement program halts progression of early coronary atherosclerosis documented by ultrafast computed tomography. J Appl Nutr 1996; 48:67-78.

43. Oliver JJ, Webb DJ. Noninvasive assessment of arterial stiffness and risk of atherosclerotic events. Arterioscler Thromb Vasc Biol 2003;23:554-66.

44. Plotnick GD, Corretti MC, Vogel RA, Hesslink R Jr, Wise JA. Effect of supplemental phytonutrients on impairment of the flowmediated brachial artery vasoactivity after a single high-fat meal. J Am Coll Cardiol 2003;41 (10):1744-9.

45. Callister TQ, Raggi P, Cooil B, Lippolis NJ, Russo DJ. Effect of HMG-CoA reductase inhibitors on coronary artery disease as assessed by electron-beam computed tomography. $N$ Engl J Med 1998;339:1972-8.

46. Zimlichman R, Shargorodsky M, Boaz M, Duprez D, Rahn KH, Rizzoni $\mathrm{D}$, et al. Determination of arterial compliance using blood pressure waveform analysis with the CR-2000 system: reliability, repeatability, and establishment of normal values for healthy European population - the seven European sites study (SESS). Am J Hypertens 2005;18:65-71.

Received June 26, 2006; accepted December 4, 2006 


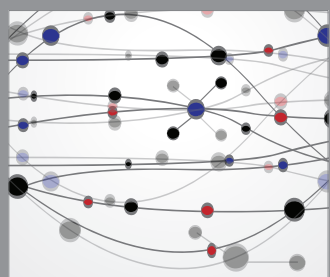

The Scientific World Journal
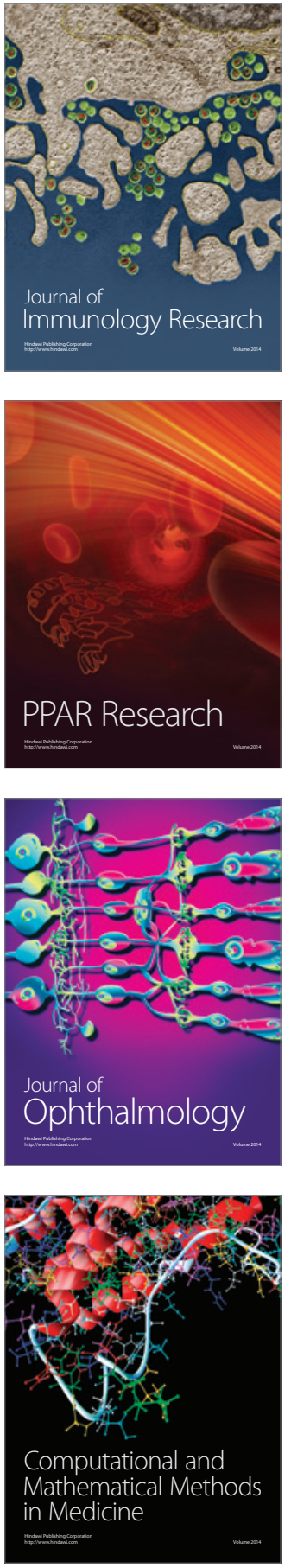

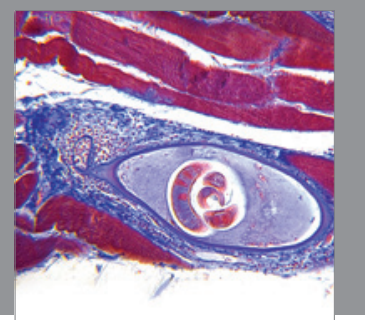

Gastroenterology

Research and Practice
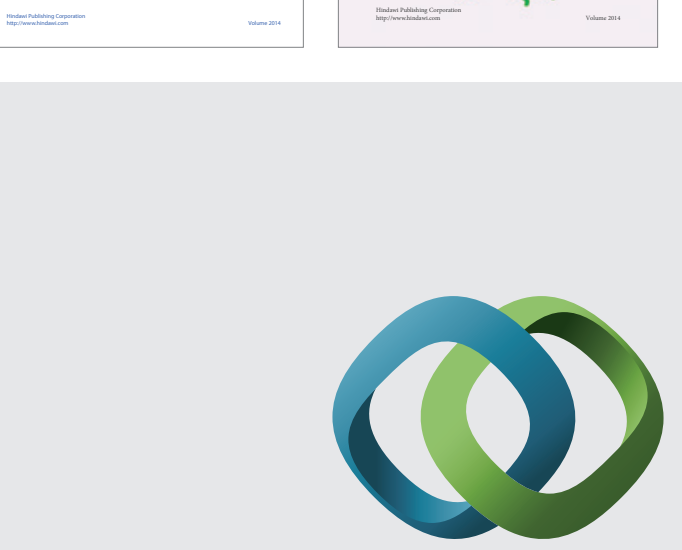

\section{Hindawi}

Submit your manuscripts at

http://www.hindawi.com
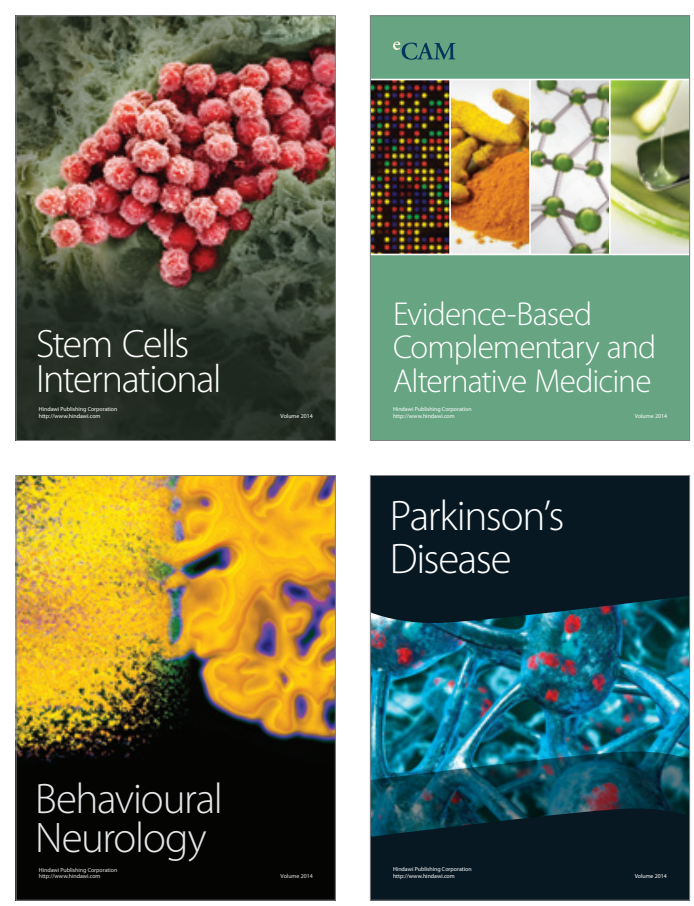

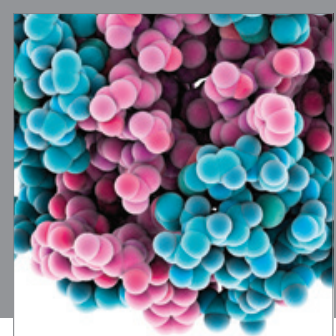

Journal of
Diabetes Research

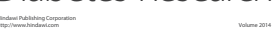

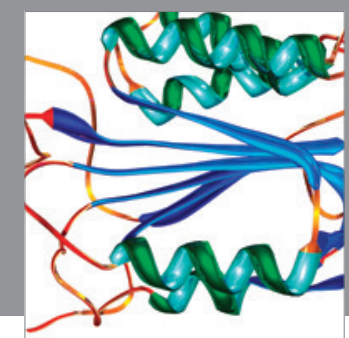

Disease Markers
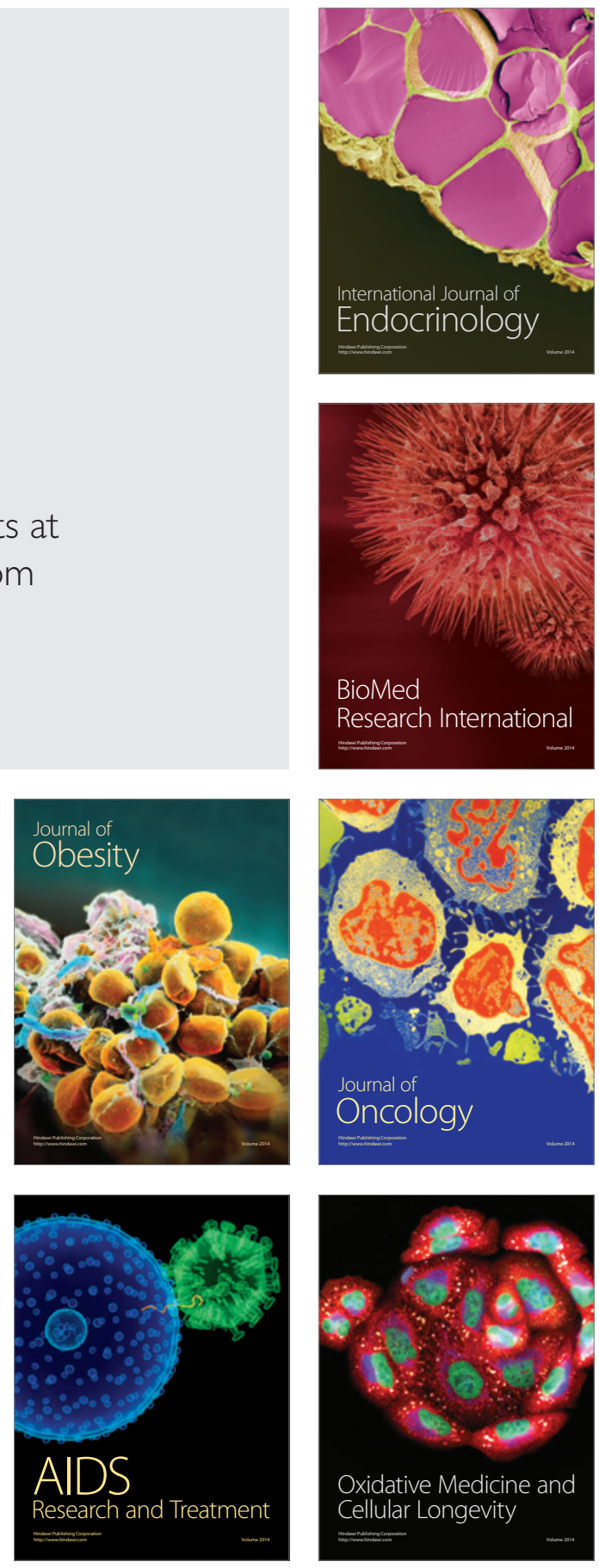